\title{
Silicone Rubber Composites of Differently Fired Cadmium Oxide and Their Positron Lifetime Study
}

\author{
Sahu $\mathrm{KR}^{1}$ and Udayan $\mathrm{DE}^{2 *}$ \\ ${ }^{1}$ Department of Physics, India \\ ${ }^{2}$ Kendriya Vihar, C-4/60, India \\ *Corresponding author: Udayan DE, Kendriya Vihar, C-4/60, India
}

Submission: 監 October 01, 2018; Published: 監 October 30, 2018

\begin{abstract}
Cadmium oxide (CdO) exhibit altered properties with altered $\mathrm{Cd}$ : 0 composition after heat treatment at different temperatures. This has been probed experimentally by various techniques. High electrical conductivity (low resistivity of $\sim 2 \mathrm{~m} \Omega \mathrm{cm}$ ) after $800{ }^{\circ} \mathrm{C}$ firing has inspired novel applications, in many of which the brittleness of the fired ceramic become a bottleneck. Here, flexible composites of these fired cadmium oxides have been formed with a silicone rubber binder and tested with respect to properties like carrier concentration and fractional free volume by positron lifetime spectroscopy. Fractional free volume, $\mathrm{V}_{p} 15.32 \%$ in the pure silicone rubber, reduces to $9.40 \%$ for the composite with $59.13 \mathrm{wt} \%$ of $800{ }^{\circ} \mathrm{C}$ fired cadmium oxide. Bulk lifetime $\tau_{\mathrm{B}}$ for positrons in a sample is shorter for higher number density of electrons in the bulk. It reduces from 203.78ps for pure silicone rubber, to $174.01 \mathrm{ps}$ for the same composite.
\end{abstract}

Keywords: Cadmium oxide; Heat treatment effects; Polymeric composites; Positron lifetime characterization; Non-stoichiometry.

\section{Introduction}

Some composites, polymer-ceramic composites, have often been designed to target specific applications. Interesting electrical or magnetic properties of certain ceramics usually come with the drawback that brittle ceramics cannot be shaped easily into bulk components or flexible sheets. Cadmium oxide (CdO), a II-VI semiconductor, appears to be a promising electromagnetic material. Cadmium oxide with rock-salt structure, is almost entirely transparent in the optical part of the electromagnetic spectrum, and has high electrical conductivity [1,2]. Particularly high room temperature conductivity has been achieved by firing at temperatures like $800{ }^{\circ} \mathrm{C}$ as detailed later. Interest in $\mathrm{CdO}$ and other transparent conducting oxides (TCOs) for more than two decades has been for optoelectronic devices operating at short wavelengths, thin-film photo-voltaics and flat panel displays. However, current decade finds use of these oxide semiconductors, with potential application in optoelectronics and high-performance electronic device applications. While $\mathrm{ZnO}$, with $3.3 \mathrm{eV}$ room-temperature band gap (Eg) and large exciton binding energy of $60 \mathrm{meV}$, is playing the main role in many II-VI optoelectronic devices, their spectral range is being extended [3] into the visible and deep ultraviolet ranges by alloying $\mathrm{ZnO}$ with the smaller band-gap compound CdO [4], having room-temperature $\mathrm{E}_{\mathrm{g}}$ of $\sim 2.2 \mathrm{eV}$ at the Brillouin-zone centre, and with larger band-gap compound $\mathrm{MgO}[3,5]$ with $\mathrm{E}_{\mathrm{g}}$ of $7.7 \mathrm{eV}$, respectively.

We find non-stoichiometry [6-10] and, hence, widely varying electrical conductivity [2] in differently heat-treated cadmium ox ide (Figure 1). Large composition variation in the $\mathrm{NaCl}$ structured CdO phase has been proved from RBS [5,7], atomic absorption spectroscopy [8], Elastic Recoil Detection Analysis [6-10] and Time of Flight Secondary Ion Mass Spectroscopy [6]. Room temperature resistivity of as-supplied E Mark (India) cadmium oxide was $97 \mathrm{~m}$ $\Omega \mathrm{cm}$. Firing [4,7] at $270{ }^{\circ} \mathrm{C}$ reduce it to $\sim 26.4 \mathrm{~m} \Omega \mathrm{cm}$. Resistivity reduces, further, to $\sim 2.1 \mathrm{~m} \Omega \mathrm{cm}$ after $800{ }^{\circ} \mathrm{C}$ heat treatment. It is a n-type semiconductor [1] (as found from Hall effect measurements in this and other work) with $\mathrm{NaCl}$ type cubic structure (XRD in Figure 2). We observed [6] weight loss at high temperatures in TGADSC experiments. The conductivity of CdO appears to be associated with its defect structure, either due to excess Cd ions in interstitial positions or due to oxygen vacancies [11]. However, the sintered pellets are brittle and resist any fabrication. So, here we have fabricated $[2,12,13]$ new composites of these differently heat-treated $\mathrm{Cd}-\mathrm{O}$ solids with an interesting silicone rubber polymer. We have discussed above how cadmium oxide is becoming technologically important. It is welcome for alloying with other oxides or doping and for forming complex with the polymer rubber to form finetuned materials. However, even the pure material is complex, exhibiting non-stoichiometry and defect structures, as a function of its preparation or heat treatment temperature. Positron annihilation spectroscopy (PAS) being a powerful tool to study defects in soft $[14]$ and hard $[4,15]$ condensed matter, we investigate silicone-rubber CdO complex samples by positron lifetime spectroscopy (PLS) $[14,15]$. 


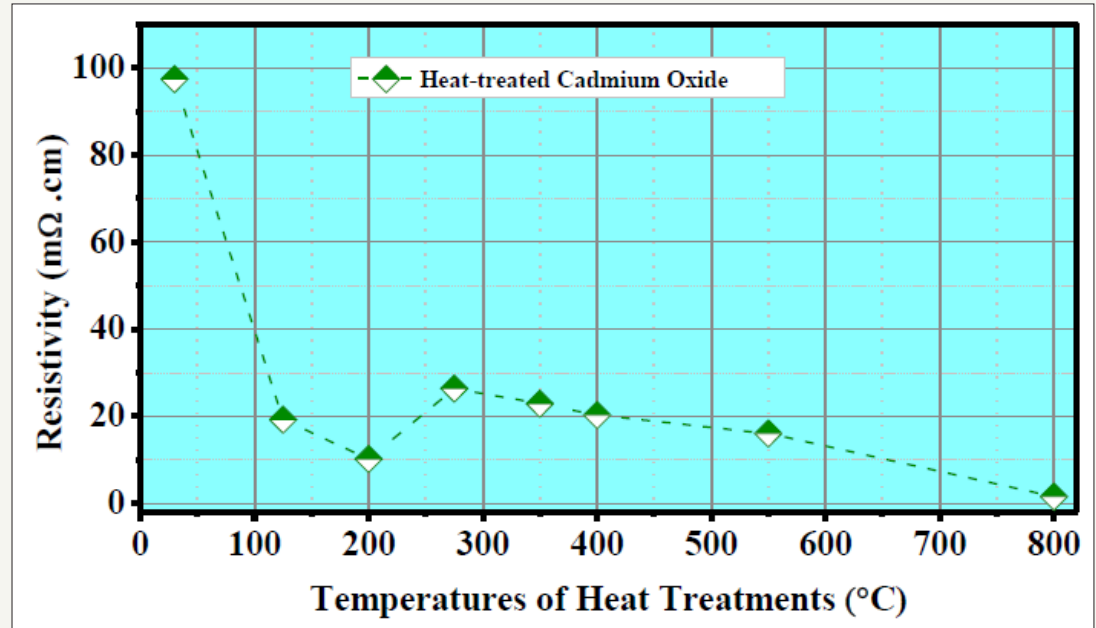

Figure 1: Variation, with firing temperature, of room temperature electrical resistivity of heat-treated Cadmium oxide. Low resistivity of $800^{\circ} \mathrm{C}$ fired "CdO" may be noted.

\section{Cadmium oxide}

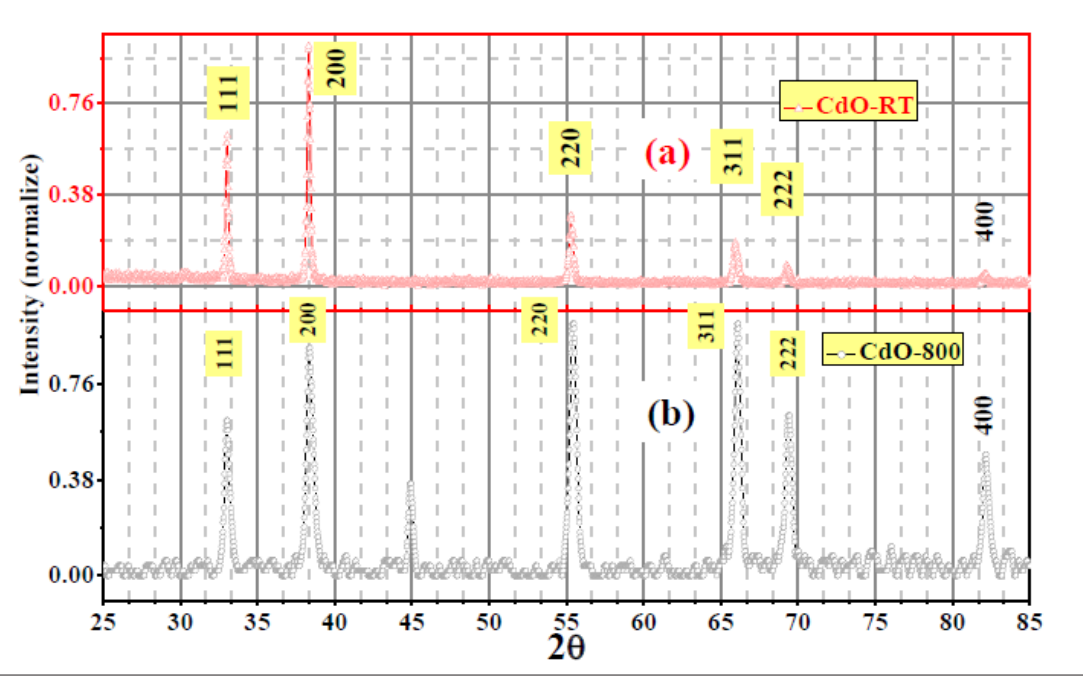

Figure 2: X-ray Diffraction (XRD) patterns for as supplied cadmium oxide (CdO-RT) and $800^{\circ} \mathrm{C}$ fired cadmium oxide (CdO-800).

There are still a few poorly understood aspects of cadmium oxide like its non-stoichiometry (Figure 2) and colour, although cadmium oxide has been well investigated experimentally and theoretically for many decades. These aspects have been somewhat addressed here. The high achievements of global CdO research include following publications in 2008 and later. Jefferson et al. [1], determined from infrared reflectivity, ultraviolet/visible absorption, and Hall effect measurements, the bandgap and band-edge effective mass of single crystal cadmium oxide, epitaxially grown by metal-organic vapor-phase epitaxy. Analysis and simulation of the optical data have yielded room temperature bandgap and bandedge effective mass values of $2.16 \pm 0.02 \mathrm{eV}$ and $(0.21 \pm 0.01) \mathrm{m}_{0}$, respectively, with $\mathrm{m}_{0}=$ band-edge effective mass. The valence-band density of states of $\mathrm{CdO}$ and similar oxides, have been determined [3] from XPS and DFT calculations. We have studied [6,9] room temperature XPS of differently fired $\mathrm{Cd}-\mathrm{O}$, finding significant electronic re-distribution due to the high temperature treatments.

\section{Experimental Outline}

\section{Characterization of differently fired CdO}

99.999\% pure Aldrich and 99.99+\% pure Ma Teck GmbH cadmium oxide ( $\mathrm{CdO}$ ) have been used. These have been supplied as brown powder. This was further ground to fine powder, and then pelletized before firing. Heat treatments (36h) have been done in air in a Carbolite Furnace with PID Temperature Controller at temperatures between $120^{\circ} \mathrm{C}$ (to drive out moisture, if any) and $800^{\circ} \mathrm{C}$. Samples have been taken out of the furnace under hot condition instead of furnace cooling, to preserve the firing temperature condition. After firing, say, at $800{ }^{\circ} \mathrm{C}$, the fired sample will be called CdO-800, and so on. XRD pattern of each sample has been taken at room temperature in a Bruker Diffractometer to know the correct phase. For the DSC or Differential Scanning Calorimetry runs in a Seiko DSC 6200 set-up, the heating has always been kept at 
$5^{\circ} \mathrm{C} / \mathrm{min}$, as higher rates mask finer features of the DSC plot. Typically, $\sim 25 \mathrm{mg}$ sample has been taken in a miniature platinum (Pt) crucible $(\sim 180 \mathrm{mg})$ on one of the two heaters in the DSC set-up. A similar Pt crucible in empty state on the other heater served as the standard for the differential measurement. A follow-up blank run of two empty crucibles has provided the background correction. A check of the set-up has been our rough measurement of the specific heat of platinum, reproducing the value $0.033 \mathrm{cal} \mathrm{g}^{-1} \cdot \mathrm{K}^{-1}$ in $20-500$ ${ }^{\circ} \mathrm{C}$ range $[16,17]$. This is encouraging, although phase transition temperatures rather than specific heat values have been of interest in the present work. Thermo-gravimetric Analysis (TGA) has been similarly done in a Seiko TGA set-up.

Table 1a: Positron lifetime results for composites of silicone rubber P2.

\begin{tabular}{|c|c|c|c|c|c|c|c|c|c|c|}
\hline Sample name & $\tau_{1}(p s)$ & $\tau_{2}(p s)$ & $\tau_{3}(\mathrm{~ns})$ & $I_{1}(\%)$ & $I_{2}(\%)$ & $I_{3}(\%)$ & $\begin{array}{l}\tau_{B}(p s)(\text { com- } \\
\text { posite })\end{array}$ & $\begin{array}{l}\tau_{\mathrm{B}}(\mathrm{ps}) \\
\text { (com- } \\
\text { posite) }\end{array}$ & $\begin{array}{l}\tau_{\text {av }}(\mathrm{ps}) \\
\text { (com- } \\
\text { posite) }\end{array}$ & $\begin{array}{l}\tau_{\text {av }}(\mathrm{ps}) \\
\text { (CdO) }\end{array}$ \\
\hline P2 & $\begin{array}{l}172.5 \\
\pm 3.8\end{array}$ & $\begin{array}{c}468.3 \pm \\
24.6\end{array}$ & $\begin{array}{c}3.207 \pm \\
0.010\end{array}$ & $\begin{array}{c}46.85 \pm \\
1.4\end{array}$ & $15.04 \pm 1.2$ & $38.1 \pm 0.16$ & 203.78 & & 244.38 & \\
\hline $\begin{array}{c}\mathrm{P} 2+\mathrm{CdO}-\mathrm{RT}(7.78 \% \\
\text { wt })\end{array}$ & $\begin{array}{l}167.4 \\
\pm 3.3\end{array}$ & $\begin{array}{l}461.9 \pm \\
26.5\end{array}$ & $\begin{array}{l}3.184 \pm \\
0.0114\end{array}$ & $\begin{array}{l}51.47 \pm \\
1.3\end{array}$ & $13.36 \pm 1.2$ & $\begin{array}{l}35.15 \pm \\
0.15\end{array}$ & 192.72 & & 228.09 & \\
\hline $\begin{array}{c}\mathrm{P} 2+\mathrm{C}- \\
\mathrm{d} 0-270(10.01 \% \\
\text { wt) }\end{array}$ & $\begin{array}{l}175.3 \\
\pm 3.5\end{array}$ & $\begin{array}{c}477.0 \pm \\
28.5\end{array}$ & $\begin{array}{c}3.183 \pm \\
0.011\end{array}$ & $\begin{array}{c}51.31 \pm \\
1.3\end{array}$ & $13.23 \pm 1.2$ & $35.44 \pm 0.17$ & 201.41 & $\begin{array}{l}173 \pm \text { at } \\
275^{\circ} \mathrm{C}\end{array}$ & 237.15 & $203 \pm 4$ \\
\hline $\begin{array}{c}\mathrm{P} 2+\mathrm{C}- \\
\mathrm{d} 0-800(59.13 \% \\
\mathrm{wt})\end{array}$ & $\begin{array}{c}152 \pm \\
3.1\end{array}$ & $\begin{array}{l}393.5 \pm \\
20.8\end{array}$ & $\begin{array}{l}3.164 \pm \\
0.014\end{array}$ & $\begin{array}{l}60.54 \pm \\
1.65\end{array}$ & $15.72 \pm 1.5$ & $23.7 \pm 0.12$ & 174.01 & $\begin{array}{l}136 \pm \text { at } \\
810^{\circ} \mathrm{C}\end{array}$ & 201.78 & $152 \pm 3$ \\
\hline
\end{tabular}

Table 1b: Positron lifetime results for composites of silicone rubber P4.

\begin{tabular}{|c|c|c|c|c|c|c|c|c|c|c|}
\hline Sample name & $\tau_{1}(n s)$ & $\tau_{2}(\mathrm{~ns})$ & $\tau_{3}(\mathrm{~ns})$ & $I_{1}(\%)$ & $I_{2}(\%)$ & $I_{3}(\%)$ & $\begin{array}{c}\tau_{\mathrm{B}}(\mathrm{ps}) \\
\text { (com- } \\
\text { posite) }\end{array}$ & $\begin{array}{l}\tau_{\mathrm{B}}(\mathrm{ps}) \\
\text { (CdO) }\end{array}$ & $\begin{array}{c}\tau_{\mathrm{av}}(\mathrm{ps}) \\
\text { (composite) }\end{array}$ & $\tau_{\mathrm{av}}(\mathrm{ps})(\mathrm{CdO})$ \\
\hline P4 & $\begin{array}{c}156.7 \pm \\
4.9\end{array}$ & $\begin{array}{c}377.1 \pm \\
22.5\end{array}$ & $\begin{array}{c}3.186 \pm \\
0.010\end{array}$ & $\begin{array}{c}44.9 \pm \\
2.1\end{array}$ & $16.9 \pm 2.0$ & $38.2 \pm 0.14$ & 186.51 & & 216.97 & \\
\hline $\mathrm{P} 4+\mathrm{CdO}-800$ & $\begin{array}{c}156.3 \pm \\
2.5\end{array}$ & $\begin{array}{c}456.1 \pm \\
28.9\end{array}$ & $\begin{array}{c}3.148 \pm \\
0.016\end{array}$ & $\begin{array}{c}66.37 \pm \\
1.18\end{array}$ & $\begin{array}{c}10.96 \pm \\
1.0\end{array}$ & $22.7 \pm 0.14$ & 172.36 & $\begin{array}{c}136 \pm 2 \\
810^{\circ} \mathrm{C}\end{array}$ & 198.79 & $152 \pm 3$ \\
\hline
\end{tabular}

Table 2: Calculation of Fractional Free Volume of pure polymers P2 and P4, and their CdO composites.

\begin{tabular}{|c|c|c|c|c|c|c|}
\hline $\begin{array}{l}\text { Sample } \\
\text { name }\end{array}$ & $\tau_{3}(n s)$ & $I_{3}(\%)$ & $\mathbf{R}_{\mathrm{o}}\left(\mathbf{A}^{\circ}\right)$ & $R\left(A^{\circ}\right)=\left[R_{o}-\Delta R\right]$ & $\operatorname{VF}\left(A^{\circ 3}\right)=(4 / 3) \pi R^{3}$ & $\begin{array}{c}V_{f}(\%)= \\
C_{F} I_{3}\end{array}$ \\
\hline P2 & $3.207 \pm 0.011$ & $38.1 \pm 0.16$ & 5.435 & 3.775 & 225.341 & 15.454 \\
\hline $\begin{array}{l}\mathrm{P} 2+\mathrm{C}- \\
\mathrm{dO}-\mathrm{RT}\end{array}$ & $3.1837 \pm 0.011$ & $35.15 \pm 0.15$ & 5.4198 & 3.7598 & 222.629 & 14.086 \\
\hline $\begin{array}{l}\mathrm{P} 2+\mathrm{C}- \\
\mathrm{d} 0-270\end{array}$ & $3.183 \pm 0.011$ & $35.44 \pm 0.17$ & 5.419 & 3.759 & 222.488 & 14.193 \\
\hline $\begin{array}{l}\mathrm{P} 2+\mathrm{C}- \\
\mathrm{d} 0-800\end{array}$ & $3.164 \pm 0.014$ & $23.7 \pm 0.12$ & 5.4069 & 3.7469 & 220.346 & 9.399 \\
\hline $\mathrm{P} 4$ & $3.186 \pm 0.010$ & $38.2 \pm 0.14$ & 5.421 & 3.761 & 222.843 & 15.323 \\
\hline $\begin{array}{l}\mathrm{P} 4+\mathrm{C}- \\
\mathrm{d} 0-800\end{array}$ & $3.148 \pm 0.016$ & $22.7 \pm 0.14$ & 5.421 & 3.736 & 218.428 & 8.925 \\
\hline
\end{tabular}

\section{Positron lifetime measurement}

Radioactive ${ }^{22} \mathrm{Na}$ is the most commonly used PLS probe. It emits a prompt gamma-photon of $1.276 \mathrm{MeV}$ almost simultaneously with the positron (Figure 3), and the prompt gamma-ray can be consid-

\section{Composites of differently fired $\mathrm{CdO}$ and silicone}

Composites have been prepared with the Silicone Polymeric Binder 732 RTV (to be called P2) or 734 RTV (to be called P4) manufactured by Dow Corning. It is a thick liquid inside its tube. Overnight curing in air of the binder or the binder-solid composite resulted in rubber-like sheets of controllable thicknesses and sizes. In this way, composites (Tables 1 \& 2) were prepared from P2 or $\mathrm{P} 4$ and fine powders of unfired or fired cadmium oxide. The ingredients have been mixed in various proportions. Each composition was mixed homogeneously and allowed to cure overnight on glass plate in air. 
of mass frame. This annihilation gamma-ray can be considered as the death signal of the positron. The ${ }^{22} \mathrm{Na}$ source is sandwiched (Figure 4) between two tablets of the sample, so that all the emitted positrons will annihilate with the electrons of the sample. The time (t) that elapses between the detections of the $1276 \mathrm{keV}$ and $511 \mathrm{keV}$ photons by the two scintillation detectors $\left(\mathrm{BaF}_{2}\right.$ scintillators with PMTs), acting as start and stop signals for a time-amplitude-converter (TAC), is the positron lifetime in that sample or that material. The lifetime spectrum $\mathrm{N}(\mathrm{t})$ vs. $\mathrm{t}$ is recorded in a computer-based MCA. Higher electron density leads to shorter lifetime in the bulk.

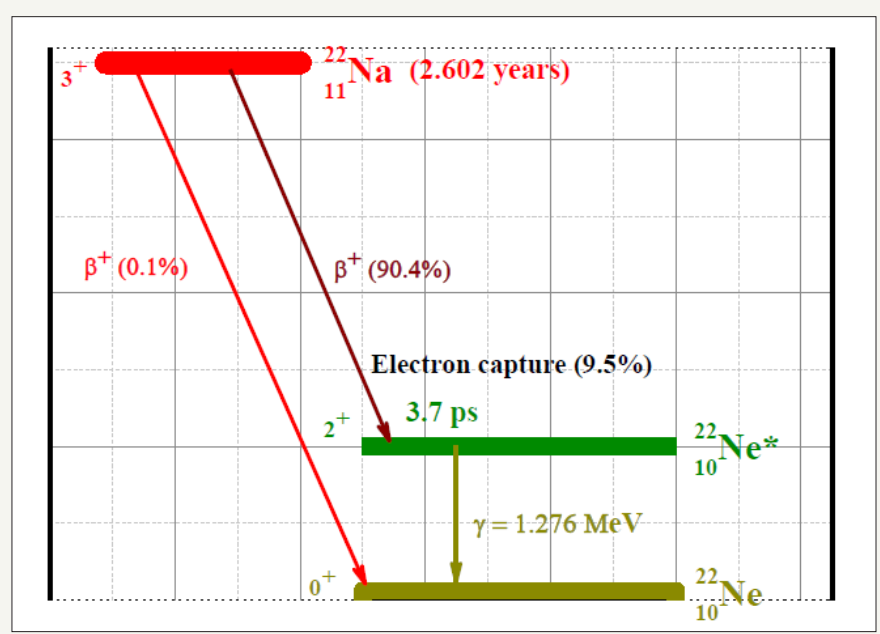

Figure 3: Decay scheme of the radioactive isotope $22 \mathrm{Na}$, present PAS probe. This has been embedded in the Source (vide Figure 4) as a layer of $\mathrm{NaCl}$. Most $(90.4 \%)$ of the $22 \mathrm{Na}$ atoms decay by emission of a positron and an electron neutrino to the excited state $22 \mathrm{Ne}^{*}$. $22 \mathrm{Ne}^{*}$ has a very short lifetime (3.7ps) to decay into the ground state by the emission of a $\gamma$-quantum of $1.27 \mathrm{Mev}$. So, this $\gamma$-quantum of $1.27 \mathrm{Mev}$ is the birth signal of the positron, important for PAS (Positron Annihilation Spectroscopy). Competitive processes of electron capture (EC) and direct transition to the Ne ground state are of much lower probabilities.

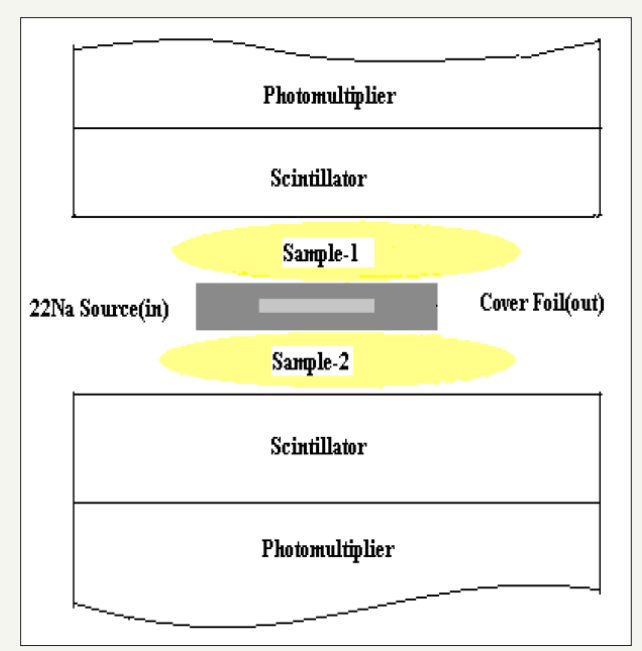

Figure 4: The schematic diagram shows the sample-source sandwich arrangement to let the positrons from the source migrate into Sample 1 or 2 . Registering (i) the $1.27 \mathrm{MeV}$ prompt photon as the birth signal of a positron (start for a time-amplitudeconverter or TAC), and (ii) one of the two $511 \mathrm{keV}$ annihilation $\gamma$-rays as death signal for the positron (stop signal for the TAC) measures the positron lifetime. The $\gamma$-quanta are detected as light flashes or photons in the scintillator. These photons are converted into electrical pulses in the photo-multipliers

$\mathrm{N}(\mathrm{t})$ vs. $\mathrm{t}$ graph for ceramics and polymers often consists of three lifetime components, $t_{i}=1,2,3$ with intensities $I_{i}$. Pure annealed metal standards show only one lifetime component. The longest componen $t_{3}$ (with intensity $I_{3}$ ) is the lifetime of positronium (ps) atoms formed in holes or voids in the sample. The positronium (Ps) lifetime ( $\sim 1$ to $\sim 3 \mathrm{~ns}$ ) is longer in larger holes. $\mathrm{I}_{3}$ is supposed to give fraction of holes of size corresponding to $t_{3}$. Here, following [18-20]

$$
\tau_{3}=0.5\left[1-R / R_{0}+(1 / 2 \pi) \sin \left(2 \pi R / R_{0}\right)^{-1}\right]
$$

with $\mathrm{R}_{0}$ representing the total radius of the hole (assumed to be spherical), where positroniums (Ps) are localized. $\mathrm{R}$ is the radius of the free volume hole, and $R=R_{0}-R$. Here, $R$ is the thickness of the uniform electron layer, accepted as $\mathrm{R}=1.66 \AA$.

So, average free volume, $V_{F}=(4 / 3) R^{3}\left(\AA^{3}\right)$. 
Free volume fraction, $\mathrm{V}_{\mathrm{f}}=\mathrm{CV}_{\mathrm{F}} \mathrm{I}_{3}(\%)$, accepting $\mathrm{C}=1.810^{-3} \AA^{-3}$.

Also, average lifetime tav and bulk lifetime $\tau_{\mathrm{B}}$ are $[15,19,21]$

$$
\begin{aligned}
& \tau_{a v}=\left(\tau_{1} I_{1}+\tau_{2} I_{2}\right) /\left(I_{1}+I_{2}\right) \\
& \tau_{B}=\left(I_{1}+I_{2}\right) /\left(I_{1} / \tau_{1}+I_{2} / \tau_{2}\right)
\end{aligned}
$$

\section{Results and Discussion}

Cadmium oxide, CdO, is usually supplied by manufacturers as a light brown powder. It is the most ionic II-VI compound that should have high resistivity. We measured, by vander Pauw (vdP) 4-probe technique, its room temperature resistivity to be high: $97 \mathrm{~m} \Omega \mathrm{cm}$. It is remarkable that after $800{ }^{\circ} \mathrm{C}$ firing of the as-supplied sample for 36 hours, we got black coloured semi-metallic sample of only $\sim 2.2 \mathrm{~m} \Omega \mathrm{cm}$ room temperature resistivity. This and related colour changes have not been well recorded or explained in the literature. Many compounds or phases (like $\mathrm{CdO}_{2}$ ) are known for cadmium and oxygen $[22,23]$. However, same XRD peaks visually at same positions for differently fired cadmium oxide (Figure 2), prove these to represent the same "CdO" phase of the phase diagram. Significant changes of peak heights imply defect structures, atomic re-distribution and non-stoichiometric compositions. To understand the origin of generated electrical conductivity, we carried out Hall measurements (Table 3 ) at $4.8 \mathrm{kG}$ on differently fired cadmium oxide samples. This showed negative Hall Coefficient proving electrons to be the charge carriers. Such negative free carriers must have been generated by excess $\mathrm{Cd}$ ions or oxygen deficit, as mentioned earlier in this work.
Table 3: Room Temperature (RT) Hall measurement results for differently fired cadmium oxide using a magnetic field of 0.48 Tesla

\begin{tabular}{|c|c|c|}
\hline $\begin{array}{c}\text { Heat Treatment Temperature } \& \\
\text { Supplier }\end{array}$ & $\begin{array}{c}\mathbf{3 0 0}^{\circ} \mathbf{C} \\
\text { Aldrich }\end{array}$ & $\mathbf{8 0 0}^{\circ} \mathbf{C}$ Aldrich \\
\hline $\begin{array}{c}\text { RT Carrier concentration }(\mathrm{n}) \text { in }\left(1 / \mathrm{cm}^{3}\right) \\
\mathrm{X} 10^{18}\end{array}$ & 13.87 & 20.46 \\
\hline RT Mobility $\mu$ from $\sigma=n e \mu$ in $\mathrm{cm}^{2} / \mathrm{Vs}$ & 7.25 & 131.2 \\
\hline
\end{tabular}

Having explained the electrical conductivity of differently fired $\mathrm{CdO}$, we proceed to their composites with the silicone rubber. As-supplied CdO or CdO-RT loses weight or mass (TGA graph in Figure 5) basically at two temperatures $\left(236{ }^{\circ} \mathrm{C}\right.$ and $\left.\sim 381^{\circ} \mathrm{C}\right)$ that correspond to two endothermic dips in the DSC plot (DSC graph in Figure 5). The DSC result allows us to go deeper into the 2-step 0-loss from the $\mathrm{NaCl}$ structure of cadmium oxide. O-loss at around $236^{\circ} \mathrm{C}$ can start an atomic re-arrangement on further heating. The majestic exothermic peak at $270^{\circ} \mathrm{C}$ implies a lower potential energy structure or state at $270^{\circ} \mathrm{C}$ (Figure 6). So, atomic re-arrangement takes place during the progress of TGA to lead to a more tightly bound lower potential energy state at around $270^{\circ} \mathrm{C}$. So, next steep O-loss from this state requires a higher temperature (T), $\sim 381^{\circ} \mathrm{C}$. This also supports the fact that there is practically no 0-loss in TGA of the $800^{\circ} \mathrm{C}$ fired sample as shown in Figure $6 \mathrm{a} \& 6 \mathrm{~b}$. DTGA or temperature derivate of the TGA signal is shown in Figures $5 b$ \& $6 a$ to check sharp changes in TGA vs. T graphs.

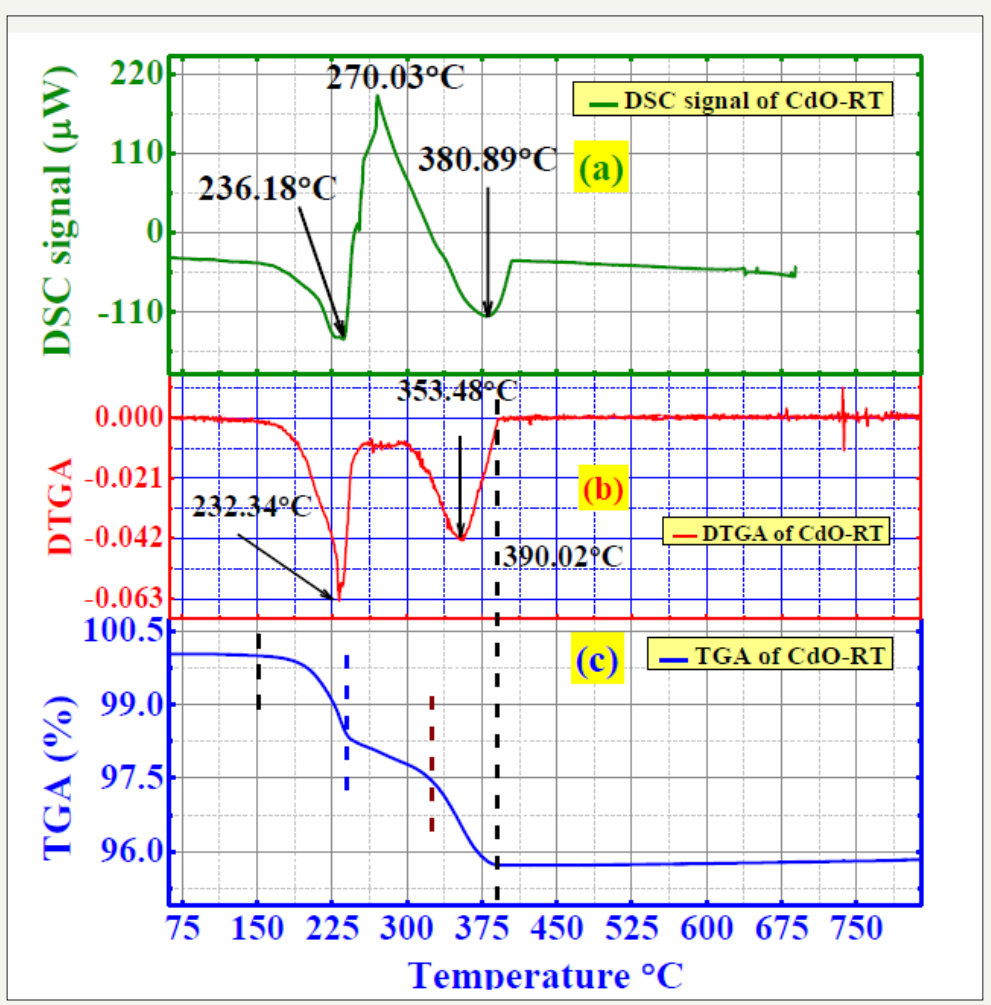

Figure 5: (a) DSC or Differential Scanning Calorimetry of as received cadmium oxide, CdO-RT. (b) DTGA or temperature derivate of TGA (Thermo-Gravimetric Analysis). (c) TGA pattern. 


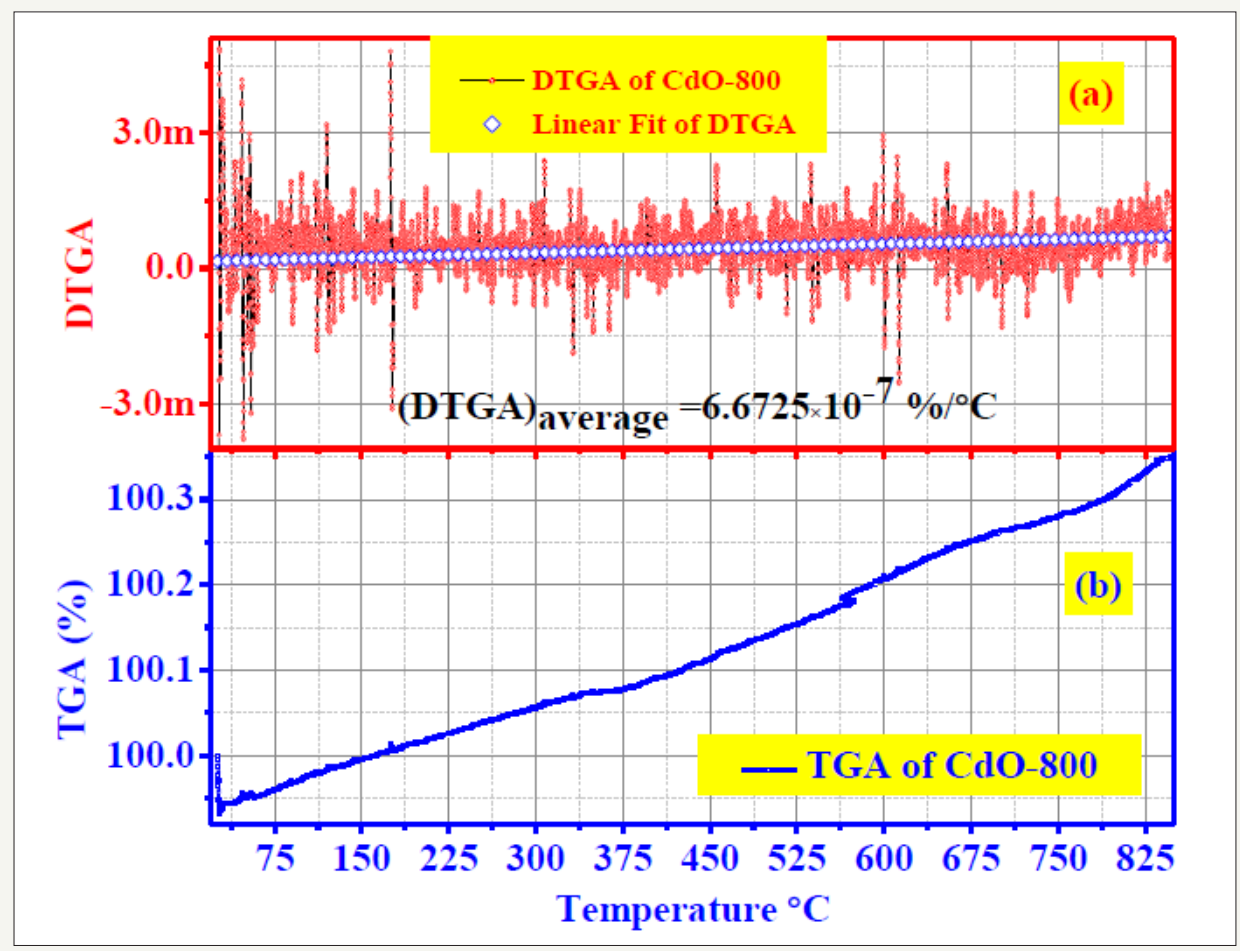

Figure 6:

6a: Thermo-gravimetric Analysis (TGA) on powdered CdO-800 sample, already fired at $800{ }^{\circ} \mathrm{C}$,

6b: Heating up to $825{ }^{\circ} \mathrm{C}$ results in no mass loss. Gain in mass, only $6.6725 \times 10-7 \% /{ }^{\circ} \mathrm{C}$, is insignificant and not understood.

Many polymers have large free volume fraction. Of the three positron lifetime components, the longest component, $\tau_{3}$, originates from voids where positroniums form and reside for time $t_{3}$ till annihilation $[15,21,24]$. So, $\mathrm{I}_{3}$ indicates their number. Table 1 a shows that $\mathrm{I}_{3}$ reduces from $\sim 38 \%$ in pure $\mathrm{P} 2$ polymer to $\sim 35 \%$ on adding 7.78wt\% CdO-RT or $\sim 10.01 \mathrm{wt} \%$ CdO-270. This corresponds Table 2 to the free volume fraction $\mathrm{V}_{\mathrm{f}}=\mathrm{CV}_{\mathrm{F}} \mathrm{I}_{3}$ of $15.45 \%$ in pure $\mathrm{P} 2$ reducing to $14.09 \%$ for the CdO-RT addition and to $14.19 \%$ for CdO-270 addition. Adding large amount of $59.13 \%$ CdO-800 reduces $\mathrm{I}_{3}$ significantly to $(23.7 \pm 0.12) \%$ with $t_{3}$ remaining practically the same. Similar addition in P4 reduces $\mathrm{I}_{3}$ to a similar value $(22.7 \pm 0.14)$, Table $1 \mathrm{~b}$. In fact, Table $1 \mathrm{~b}$ shows the polymer P4 to have almost identical $\mathrm{t}_{3}(=(3.18 \pm 0.01) \mathrm{ns})$ as $\mathrm{P} 2$, as expected. Table 2 shows that the free volume fraction $\mathrm{Vf}$ reduces from $15.45 \%$ in pure $\mathrm{P} 2$ to $9.399 \%$ in $\mathrm{P} 2+59.13 \%$ CdO-800. This compares well with $\mathrm{V}_{\mathrm{f}}=8.925 \%$ in similar P4+Cd0-800. Bulk lifetime $\left(\tau_{B}\right)$ is the lifetime of the probing positrons in the bulk, while lifetime component $\tau_{2}$ with $\tau_{2}>\tau_{B^{\prime}}$ is the lifetime of positrons trapped at defects (like positive-ion vacancies). Adding n type CdO-800 to P2 or P4 indeed reduces bulk lifetime due to more electrons being available for electron-positron annihilation. Lifetime component $\tau_{2}$ exists and is larger than $\tau_{\mathrm{B}}$ for all sample to indicate trapping by defects in cadmium oxide.

\section{Summary and Conclusion}

Novel properties and non-stoichiometry in differently fired cadmium has been probed by a host of characterization techniques. Next, their composites with a silicone rubber binder have been formed at different concentrations to get flexible cloth-like composites with the advantages of cadmium oxide. Flexible electromagnetic (EM) shielding [13] has been one of the applications in mind. Current positron lifetime measurements in the composites prove that cadmium oxide enters the free volume of the polymeric binder to form the composites. The measurements also show higher number density of electrons in polymer-embedded $800^{\circ} \mathrm{C}$ fired $\mathrm{CdO}$ (CdO800 ) in line with higher electrical conductivity measured in pure CdO-800. So, the composites are seen to retain the advantage of high electrical conductivity, while providing flexible samples. These composites and other silicone rubber-based composites have been used $[12,13]$ for EM Interference (EMI) shielding applications.

\section{Acknowledgement}

Authors gratefully acknowledge advice and help from Dr. D. Das and his group in using the PLS set-up at UGC-DAE Consortium for Scientific Research, Kolkata Centre, India.

\section{References}

1. Jefferson PH, Hatfield SA, Veal TD, King PDC, McConville CF, et al. (2008) Bandgap and effective mass of epitaxial cadmium oxide. Appl Phys Lett 92(2).

2. Sahu KR, De U (2016) UHF and X band electro-magnetic shielding of advanced devices by some polymer-composites, Material Science Research India 13(2): 80-94.

3. King PDC, Veal TD, Schleife A, Pérez ZJ, Martel B, et al. (2009) Valence-band electronic structure of $\mathrm{CdO}, \mathrm{ZnO}$, and $\mathrm{MgO}$ from x-ray photoemission spectroscopy and quasi-particle-corrected density-functional theory calculations. Phys Rev B. 
4. Sarkar A, Chattopadhyay S, De U (2009) Electrical resistivity peculiarities and positron annihilation in heat-treated CdO. Phys Status Solidi C 6 (11): 2526-2529.

5. De U, Paramanik D, Kumar R, Prasad R, Kulriya PK, et al. (2006) Atomic defects in differently fired magnesium oxide, international conference on atomic collisions in solids (ICACS-2006), Berlin.

6. De U (2011) Characterizations of advanced materials and some new applications. J Asiat Soc Bangladesh Sci 37(2): 479-501.

7. De U, Verma KC, Karmakar P, Sarkar A, Dey S, et al. (2003) Resonance scattering and RBS from non-stoichiometric oxides. Nuclear Instru. \& Methods in Phys Res 212: 505-509.

8. De U, Venkatesh M, Shaikh MS, Venkataramani B (2008) Study of elemental composition in some II-VI oxides by atomic absorption spectroscopy. Ind J Phys 82(3): 259-263.

9. De U, Kumar R, Paramanik D, Verma S, Prasad R (2006) XPS \& RBS study of thermally induced oxygen non-stoichiometry in $\mathrm{Zn} \& \mathrm{Cd}$ oxides. International Conference on Atomic Collisions in Solids (ICACS-2006), Germany.

10. Bohne W, Röhrich J, Röschert G (1998) The berlin time-of-flight ERDA setup. Nucl Instrum and Meth 136-138: 633-637.

11. Choi JS, Kang YH, Kim KH (1977) Electrical conductivity of cadmium oxide. J Physical Chemistry 81(23): 2208-2211.

12. Sahu KR, De U (2017) Flexible electromagnetic shielding by polymer-metal and polymer-non-metal composites. SF J Metallurgical Science $1: 2$.

13. Sahu KR, De U (2018) Polymer composites for flexible electromagnetic shields. published in Macromolecular Symposia - ICNP2017Rio 381(1): 1800097.

14. Banerjee S, Deka M, Kumar A, De U (2013) Ion irradiation effects in some electro-active and engineering polymers: studies by conventional and novel techniques, in defect and diffusion forum. Trans Tech Publications 341: 1-49.
15. De U, Sanyal D (1999) Probing HTSC by positron lifetime and doppler broadening investigations in studies of high temperature superconductors - advances in research and applications. Nova Science Publishers Inc. New York

16. White WP (1918) The specific heat of platinum at high temperatures. Phys Rev 12(6): 436-441.

17. Sahu KR, De U (2009) Thermal characterization of piezoelectric and non-piezoelectric lead meta-niobate. Thermochimica Acta 490(1-2): 75 77.

18. Yao XF, Yeh HY, Zhou D, Zhang YH (2006) The structural characterization and properties of sio $_{2}$-epoxy nanocomposites. Journal of Composite Materials 40(4): 371

19.Dlubek G, De U, Pionteck J, Arutyunov NY, Edelmann M, et al. (2005) Temperature dependence of free volume in pure and silica-filled poly (dimethyl siloxane) from positron lifetime and pvt experiments. Macromol Chem Phys 206(8): 827-840.

20. Shpotyuk O, Ingram A, Shpotyuk Ya (2018) Free-volume characterization of nano structurized substances by positron annihilation lifetime spectroscopy. Nuclear Instruments and Methods in Physics Research Section B: Beam Interactions with Materials and Atoms 416: 102-109.

21. De U, Chaudhuri SK, Sahu KR, Das D, DuttaGupta N, et al. (2009) Positron lifetime in piezoelectric $\mathrm{PbNb} 2 \mathrm{O} 6$ and $\mathrm{BaTiO}_{3}$ polycrystals. Phys Status Solidi C 6(11): 2513-2515.

22. Zaoui A, Ferhat M (2017) Exploring novel phases of Cd-O system at ambient pressure. Physics Letters A 381(7): 685-688.

23. Zhu YZ, Chen GD, Ye HG, Walsh A, Moon CY, et al. (2008) Electronic structure and phase stability of $\mathrm{MgO}, \mathrm{ZnO}, \mathrm{CdO}$, and related ternary alloys. J Physical Review B 77(24): 245209.

24. Tao SJ (1972) Positronium annihilation in molecular substances. J Chem Phys 56: 5499-5510.
Creative Commons Attribution 4.0 International License

For possible submissions Click Here
Submit Article

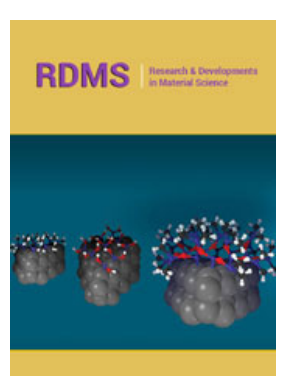

Research \& Development in Material Science

Benefits of Publishing with us

- High-level peer review and editorial services

- Freely accessible online immediately upon publication

- Authors retain the copyright to their work

- Licensing it under a Creative Commons license

- Visibility through different online platforms 